\title{
Racial differences in the patterns of preterm delivery in central North Carolina, USA
}

\author{
Cheryl A. Blackmore*t, David A. Savitzt, Lloyd J. \\ Edwardsł, Siobán D. Harlow§ and Watson A. Bowes \\ Jr.I \\ *Division of Reproductive Health, National Center for Chronic Disease \\ Prevention and Health Promotion, Centers for Disease Control and \\ Prevention, Atlanta, Georgia, Departments of + Epidemiology and \\ $\ddagger$ Biostatistics, University of North Carolina School of Public Health, \\ IDepartment of Obstetrics and Gynecology, University of North \\ Carolina School of Medicine, Chapel Hill, North Carolina and \\ §Department of Epidemiology, University of Michigan School of \\ Public Health, Ann Arbor, Michigan, USA
}

Summary. In order to assess racial differences in rates of idiopathic preterm labour, preterm premature rupture of membranes, and medically indicated preterm delivery, the authors analysed data on 388 preterm ( $<37$ completed weeks of gestation) births ( $7.9 \%$ of all births) occurring between 1 September 1988 and 31 August 1989, in three central North Carolina counties. The crude relative risk (RR) of preterm birth among black women compared with white women was 2.6 [95\% confidence interval (CI) 2.1, 3.1]. With adjustment for age, gravidity, marital status, education, and county of residence, the estimated relative risk for black women compared with white women was $2.1(95 \% \mathrm{CI} 1.1,4.1)$ for medically indicated preterm delivery, $1.6(95 \% \mathrm{CI} 1.1,2.3)$ for preterm birth as a result of preterm labour, and $1.9(95 \% \mathrm{CI} 1.2,3.1)$ for preterm premature rupture of membranes. Compared with white women, black women were at the highest risk of a preterm birth before 34 weeks of gestation $(R R=2.9$; $95 \% \mathrm{CI} 1.8,4.7)$. The risk of medically indicated preterm delivery at 36 weeks was considerably higher for black women than for white women $(R R=3.4 ; 95 \% \mathrm{CI} 1.1,10.2)$. For a better understanding and ultimately a reduction of the risk for preterm delivery among black women, investigation of specific aetiological pathways and gestational age groups may be required.

Address for correspondence: Dr Cheryl A. Blackmore, Division of Reproductive Health, Centers for Disease Control and Prevention, 4770 Buford Highway, NE, Mail Stop K23, Atlanta, GA 30341-3724, USA. 


\section{Introduction}

Preterm delivery, the termination of a viable pregnancy before completion of the 37th week of gestation, is one of the predominant proximate causes of lowbirthweight birth and is the third leading cause of infant mortality in the United States. ${ }^{1}$ According to the National Center for Health Statistics, 436590 preterm births (10.6\% of all livebirths) occurred in the United States in 1990; $8.9 \%$ of white infants were born preterm whereas the risk of black preterm births was $18.8 \%$ during the same period. ${ }^{2}$ Moreover, for black women, preterm delivery is the leading cause of infant mortality. ${ }^{1}$

The reasons for this disparity are largely unexplained. ${ }^{3-7}$ Differences in maternal age, education, marital status, income and lack of prenatal care reportedly account for a major portion of the discrepancy, but they do not fully explain the gap or suggest specific interventions to reduce this racial disparity. 5,7

Preterm delivery is an adverse reproductive outcome initiated primarily by one of three processes: idiopathic preterm labour in which labour begins spontaneously, preterm premature rupture of membranes in which the chorioamniotic membrane breaks spontaneously before labour, or intentional medical/surgical intervention such as induction of labour or Caesarean section. Hence, in studies of the aetiology of preterm delivery, treating these three different processes as if they were a single entity may not be appropriate. Prevention of preterm delivery may in fact require a better understanding of its heterogeneous aetiology. Unfortunately, data on the prevalence of each condition are lacking. Preliminary data suggest that medically indicated preterm delivery is far less common than idiopathic preterm labour or spontaneous preterm premature rupture of membranes. ${ }^{8-10} \mathrm{How}$ much of the total preterm delivery rate is accounted for by each aetiological pathway is unknown.

Population-based studies of the racial differences in the risks of preterm labour and premature rupture of membranes have rarely been conducted for US women, and studies using detailed information from medical records are even more rare. ${ }^{8,11}$ Most literature on the differences in aetiological pathways has focused on obstetrical intervention ${ }^{12,13}$ and clinical management. ${ }^{14}$ Little work has been carried out to identify risk factors which may be more influential for one condition than for another. Given the differences in the risks of preterm birth between black and white women, an examination of preterm delivery and its heterogeneous components may shed light on the reasons for this racial disparity. Therefore, the goal of this research was to characterise black/white differences in the risk of idiopathic preterm labour, preterm premature rupture of membranes and medically indicated preterm delivery in a population-based study. 


\section{Materials and methods}

We conducted a study of the cohort of all hospital births to women at least 18 years old who resided and gave birth in Alamance, Durham and Orange Counties, North Carolina between 1 September 1988 and 31 August 1989.

\section{Study design}

Eligible participants were either black or white women of at least 18 years of age. (Young teenagers were excluded from the study for medicolegal reasons.) Any woman who gave up her infant for adoption at the time of delivery was ineligible to participate because it was presumed that she might be reluctant to be interviewed about that birth. The five hospitals (two Level III, one Level II and two Level I) which were located in Alamance, Durham and Orange counties delivered nearly $97 \%$ of all women residents of these three counties. A small number of women $(<4 \%)$ residing in the study area delivered at home or in a hospital in an adjacent county and were therefore excluded. We also excluded women whose index pregnancy was terminated by a spontaneous or induced abortion or an intrauterine fetal death and women who had a multiple birth. Therefore, the final study population consisted of all single livebirths occurring in all hospitals in Alamance, Durham, and Orange counties, North Carolina to resident women of those counties who were of black or white ethnicity, at least 18 years of age and did not give their infant up for adoption.

We used information from hospital records and birth certificates to determine risks of preterm delivery in the aggregate as well as risks for each of the three aetiological pathways. The Division of Statistics in the North Carolina State Center for Health and Environmental Statistics provided demographic data on the birth cohort. However, because the aetiology of preterm birth was not accurately reported on birth certificates at the time of the study, an ongoing case-control study (the Pregnancy Outcome Study), which ascertained all preterm births from hospital records of mothers residing in these three counties during the same period, was the source of data on gestational age, preterm labour, preterm premature rupture of membranes and medically indicated preterm birth.

In the Pregnancy Outcome Study, eligible preterm births were identified by reviewing monthly computer printouts from the obstetrics department, the labour and delivery logbook, or both, depending on the institution involved. These two data sources contained the names and hospital identification numbers of all women who had delivered in that specific facility. They also provided the women's county of residence, race, the date and time of delivery, and the infant's estimated gestational age. We reviewed the medical records of all eligible women who were identified as having delivered a live singleton infant after 37 weeks or less gestation. Medical record data were then used to calculate and reconfirm or correct gestational ages and to determine the aetiological pathway. Medical records were 
also used to obtain information on race, age, education, marital status, gravidity and county of residence for the preterm births.

\section{Linking data sources}

We developed contingency tables for black and white women by each of the five other study variables: gravidity (primigravid, multigravid), marital status (married, unmarried), age group (18-19, 20-34 and $\geq 35$ years), highest educational level attained $(<12,12,13-15$ and $\geq 16$ years) and county of residence (Alamance, Durham or Orange). Because the public-use tape of birth certificate data did not provide the mother's name, birth date, or other exact identifiers, we constructed a group identifier for each woman who had a preterm birth consisting of her demographic profile as described by the six previously mentioned study variables. We then categorically linked the preterm births to the vital records data, using the six variables. When a particular stratum contained more than one woman with identical characteristics, only the first women was chosen as the presumed link with the preterm birth.

Information was missing for a total of $58(15 \%)$ women with preterm births on at least one of three variables: marital status, gravidity, or education. To avoid losing information from these women we imputed missing data in the following way: using the entire study population as the standard, we ascertained the frequency distribution of each missing variable for women who otherwise had identical demographic profiles. We then assigned the most frequent value of the missing variable to the woman with missing information. When more than one woman with the same demographic profile was lacking the same variable, we randomly selected the most probable correct value to impute for each woman. When a preterm birth record did not match any vital records data because the value given for a variable in the study was beyond a plausible range (e.g. an 18-year-old mother was reported as having 16 years of education), the implausible value was considered missing and was reassigned according to the method described above. After these adjustments had been made to the data, the linking procedure was completed.

\section{Preterm definitions}

All deliveries that occurred more than 21 days before the woman's best calculated expected date of delivery (EDD) and after at least 21 weeks of gestation, were defined as preterm. All deliveries occurring at or after 37 weeks of pregnancy were defined as term. Because the accuracy of the last menstrual period (LMP) dates could not be confirmed, the gestational age calculated by an early ( $<25$ weeks) ultrasound was considered to be the most accurate measurement. In the absence of this measurement, the LMP was used to calculate the EDD (by adding 280 days to 
the LMP date) and gestational age was based on this reference point. When neither of these measurements was available, the gestational age was based on a physician's early ( $<20$ weeks) obstetrical examination. When none of these data was present, the gestational age was based on an evaluation of paediatric and obstetric estimates made at the time of delivery.

Women admitted to the obstetrics department are routinely asked about the occurrence and timing of membrane rupture and the onset, frequency and intensity of contractions. This information is confirmed to the extent possible by physical examination and is summarised on a standardised intrapartum recording form by the attending physician. Whenever the history provided by the mother did not correspond with the physical findings upon examination or the mother could not accurately recall the timing of these events, the relevant data were recorded in the medical record as unknown.

Women who delivered preterm and whose membranes had ruptured at least 1 hour before the spontaneous onset of labour, were defined as having preterm premature rupture of membranes. This definition excluded patients who had artificial rupture of membranes for induction of labour before contractions had begun.

Women who initially developed regular contractions and delivered before 37 weeks had the aetiology of their delivery classified as idiopathic preterm labour. This group also included women whose membrane rupture preceded the onset of contractions by less than 1 hour.

Among the remaining women who delivered preterm, those who were listed as having had induced onset of labour or who had a Caesarean section in the absence of either labour or rupture of membranes, were categorised as having had a medically indicated preterm delivery.

Women for whom the aetiology of their preterm delivery could not be determined precisely were placed in a separate category.

\section{Statistical analysis}

Initially a simple analysis was conducted, using $R R$ as the measure of effect, in order to test the crude overall association of race (treated dichotomously) with preterm labour, preterm premature rupture of membranes, and medically indicated preterm delivery. To determine if the risk of preterm birth differed by the gestational age of preterm infants, we divided the births into three groups [very preterm, $<34$ weeks (33.5\%), moderately preterm, 34-35 weeks $(32.5 \%)$ and slightly preterm, 36 weeks $(34.0 \%)]$. To assess the independent effect of race on the outcomes, we evaluated four separate logistic regression models using the nominal response variables of preterm birth, medically indicated preterm delivery, preterm labour and preterm premature rupture of membranes, adjusted for age, education, gravidity, marital status and county of residence. Women who experienced a 
Table 1. Demographic characteristics of black and white women delivering liveborn, singleton infants, central North Carolina, 1 September 1988-31 August 1989t

\begin{tabular}{lcc}
\hline Characteristics & $\begin{array}{c}\text { Black women }(\%) \\
(n=1734)\end{array}$ & $\begin{array}{c}\text { White women (\%) } \\
(n=3182)\end{array}$ \\
\hline Age (years)* & & \\
$18-19$ & 13.7 & 5.5 \\
$20-34$ & 80.5 & 82.2 \\
$\geq 35$ & 5.8 & 12.3 \\
Education (years)* & & \\
$\quad<12$ & 21.9 & 12.0 \\
12 & 43.6 & 29.3 \\
$13-15$ & 21.6 & 18.5 \\
$\geq 16$ & 13.0 & 40.2 \\
Gravidity* & & \\
Primigravida & 29.0 & 39.9 \\
Multigravida & 71.0 & 60.1 \\
County* & & 29.9 \\
Alamance & 20.5 & 44.7 \\
Durham & 67.8 & 25.5 \\
Orange & 11.7 & \\
Marital Status* & & 91.0 \\
Married & 40.7 & 9.0 \\
Not married & 59.3 & \\
\hline
\end{tabular}

* $\mathrm{P}<0.001$. tColumn percentages may not total 100 because of rounding.

preterm birth with a cause other than the one being evaluated were not included in the model. Thus, the same comparison group which consisted of only term births was used for each of the four models.

We estimated model coefficients by using unconditional maximum likelihood methods, and estimated relative risks by calculating adjusted odds ratios (ORs). All main effects and all two-way interaction terms were evaluated in the model. We evaluated interaction by using Kleinbaum's backward elimination algorithm which entails entering first-order, cross-product terms of potential confounders with the exposure and evaluating statistical significance by using likelihood ratio tests. ${ }^{15}$ To assess model parsimony, we monitored the effect on the estimated RR of deleting potential confounders from the model; $95 \%$ confidence limits for the adjusted ORs were calculated. The SAS software package (SAS Institute Inc., Cary, North Carolina, USA) was used for all analyses.

\section{Results}

A total of $1766(35 \%)$ black and $3311(65 \%)$ white women who were at least 18 years of age and who resided in Alamance, Durham or Orange Counties had singleton 


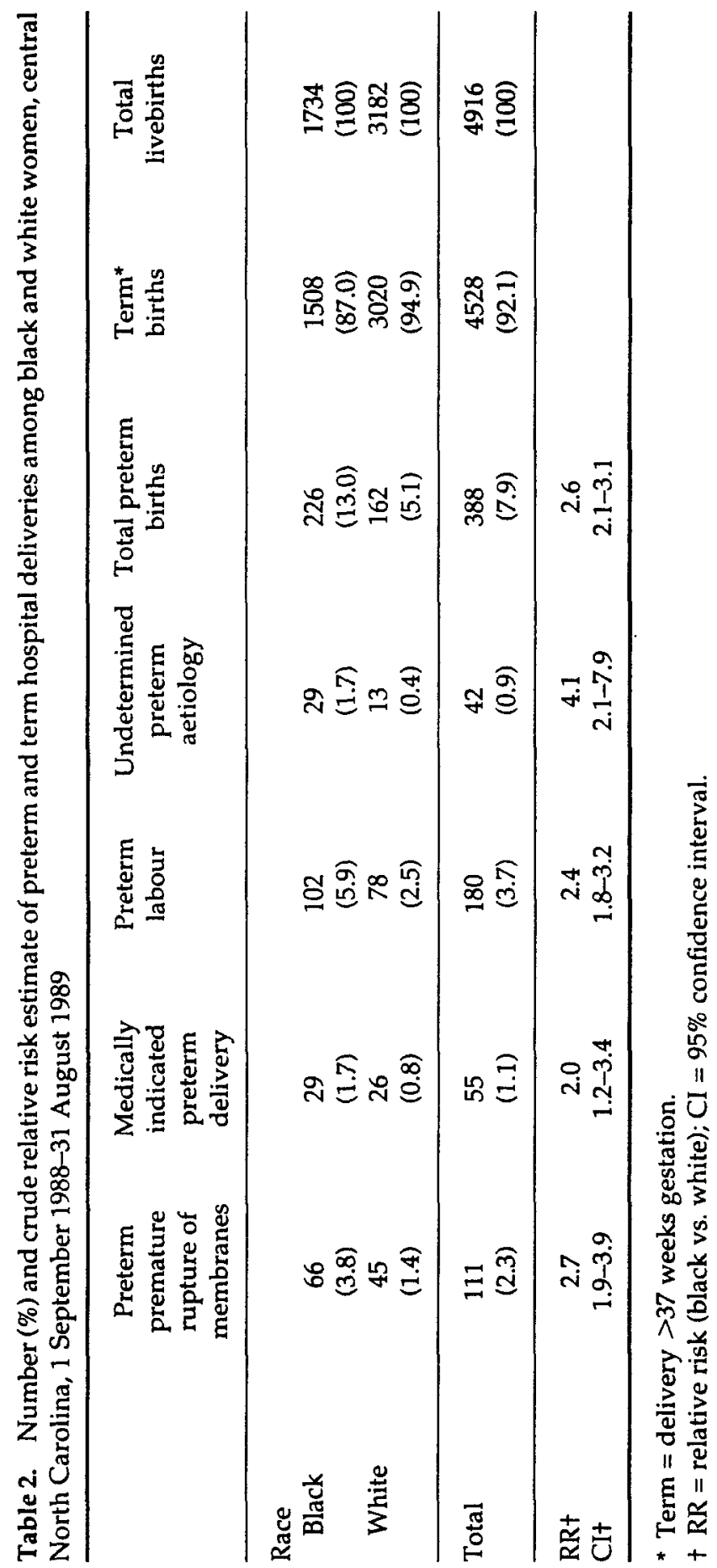

C 1995 Blackwell Science Ltd. Pacdiatric and Perinatal Epidemiology, 9, 281-295 
Table 3. Number and crude relative risk of preterm deliveries among black and white women, by gestational age group, central North Carolina, 1 September 1988-31 August 1989

\begin{tabular}{|c|c|c|c|c|c|c|}
\hline & \multicolumn{2}{|c|}{$\begin{array}{l}\text { Very preterm } \\
(20-33 \text { weeks })\end{array}$} & \multicolumn{2}{|c|}{$\begin{array}{l}\text { Moderately preterm } \\
\text { (34-35 weeks) }\end{array}$} & \multicolumn{2}{|c|}{$\begin{array}{l}\text { Slightly preterm } \\
\text { (36 weeks) }\end{array}$} \\
\hline & No. & $\%$ & No. & $\%$ & No. & $\%$ \\
\hline \multicolumn{7}{|l|}{ Race } \\
\hline Black & 91 & 5.2 & 66 & 3.8 & 69 & 4.0 \\
\hline White & 39 & 1.2 & 60 & 1.9 & 63 & 2.0 \\
\hline Total & 130 & 2.6 & 126 & 2.6 & 132 & 2.7 \\
\hline $\mathrm{RR}^{*}$ & \multicolumn{2}{|c|}{4.3} & \multicolumn{2}{|c|}{2.0} & \multicolumn{2}{|c|}{2.0} \\
\hline $\mathrm{CI}^{*}$ & \multicolumn{2}{|c|}{$3.0-6.3$} & \multicolumn{2}{|c|}{$1.4-2.8$} & \multicolumn{2}{|c|}{$1.4-2.8$} \\
\hline
\end{tabular}

* $\mathrm{RR}=$ relative risk (black vs. white); $\mathrm{CI}=95 \%$ confidence interval.

livebirths during the study period. Twenty-four of these women had home deliveries, and 137 delivered in medical facilities outside the study ascertainment area; these $161(3.2 \%)$ births were excluded from the denominator because any preterm births occurring in this population would not have been included in the casecontrol study.

Of the 1734 (35\%) black and $3182(65 \%)$ white women eligible for the study, black mothers were younger and less educated on average than white mothers (Table 1). More than two-thirds of the Black women delivering in the study area resided in Durham County. White women were twice as likely to have been married as black women.

A total of 388 births ( $7.9 \%$ of livebirths) occurred before 37 weeks of gestation in the three-county area during the study period (Table 2). Two-thirds of these preterm infants had gestational ages determined by early ultrasound (47.4\%) or LMP dating (19.1\%). We observed some substantial black/white differences in the methods used to calculate gestational age: the obstetrician's or paediatrician's subjective estimates were used for $37.2 \%$ of black women, compared with $28.4 \%$ of white women.

Among the three specific aetiologies for preterm delivery, preterm labour was the most common ( 180 cases or $3.7 \%$ of all livebirths). Medically indicated preterm delivery was the least common (55 cases or $1.1 \%$ of all livebirths). Preterm premature rupture of membranes occurred in 111 cases (2.7\% of all livebirths.) We were unable to determine the aetiology of preterm delivery for $42(0.9 \%)$ of the women in the study.

The crude RR of black compared with white preterm births was 2.6 (95\% CI 2.1, 3.1). Moreover, the increased risk of preterm delivery for black women compared with white women was apparent for each aetiological pathway. These RRs ranged from a low of 2.0 for medically indicated preterm delivery $(95 \% \mathrm{CI} 1.2,3.4)$ to a high 
of 4.1 women for whom the aetiology of their preterm delivery was undetermined (95\% CI 2.1,7.9). Additionally, the relative risk of a very preterm birth was 4.3 times higher for black women than for white women $(95 \%$ CI 3.0,6.3) whereas the risk of moderately and slightly preterm births was only doubled (Table 3 ).

In estimating $R R$ s associated with preterm birth overall and with each aetiology of preterm delivery (as determined from logistic regression models adjusting for age, education, gravidity, marital status and county of residence) we found that overall, the estimated RR of black compared with white preterm deliveries was 2.0 $(95 \% \mathrm{CI} 1.5,2.6)$ (Table 4). When the aetiologies of preterm delivery were examined separately, the estimated RR for black women compared with white women was 2.1 (95\% CI 1.1, 4.1) for medically indicated preterm delivery and 1.6 (95\% CI 1.1, 2.3) for preterm labour. For black women, the overall estimated RR of having preterm premature rupture of membranes (1.9) appeared to be modified by the effect of education, based on an absence of association for women with 13-15 years of education, although the stratum-specific estimates were imprecise. No other interaction terms were significant in any of the models evaluated.

We evaluated adjusted models for several gestational age groups to determine if the risks were consistent according to the degree of prematurity (Table 5). When

Table 4. Number and adjusted relative risk estimates for aetiologies of preterm births for black women compared with white women, central North Carolina, 1 September 1988-31 August 1989

\begin{tabular}{lcccc}
\hline Aetiology & $\begin{array}{c}\text { Black } \\
\text { births } \\
(n)\end{array}$ & $\begin{array}{c}\text { White } \\
\text { births } \\
(n)\end{array}$ & $\begin{array}{c}\text { Estimated } \\
\text { relative } \\
\text { risk* }\end{array}$ & $\begin{array}{c}95 \% \\
\text { confidence } \\
\text { interval }\end{array}$ \\
\hline $\begin{array}{l}\text { Preterm birtht } \\
\text { Medically indicated }\end{array}$ & 226 & 162 & 2.0 & $1.5-2.6$ \\
$\quad \begin{array}{l}\text { preterm delivery } \\
\text { Preterm labour }\end{array}$ & 29 & 26 & 2.1 & $1.1-4.1$ \\
Preterm premature & 102 & 78 & 1.6 & $1.1-2.3$ \\
$\quad$ rupture of membranes & 66 & 45 & 1.9 & $1.2-3.1$ \\
Preterm premature & & & & \\
$\quad$ rupture of membranes & & & & \\
stratified by & & & & \\
education (years) $\ddagger$ & 17 & 4 & 3.1 & $1.0-9.7$ \\
$\quad<12$ & 29 & 10 & 2.2 & $1.0-4.9$ \\
12 & 11 & 16 & 0.7 & $0.3-3.3$ \\
$13-15$ & 7 & 15 & 3.2 & $1.3-7.7$ \\
$\quad 16$ & & & & \\
\hline
\end{tabular}

* Adjusted models include age, education, gravidity, marital status, and county of residence.

† Includes 42 preterm births with undetermined aetiology.

\$ Educational status unknown for two black women. 
Table 5. Number and estimated relative risk for aetiologies of preterm births at specific gestational ages for black women compared with white women, central North Carolina, 1 September 1988-31 August 1989

\begin{tabular}{lccccc}
\hline $\begin{array}{l}\text { Gestational age group } \\
\text { (weeks) }\end{array}$ & $\begin{array}{c}\text { Preterm } \\
\text { premature } \\
\text { rupture of } \\
\text { membranes }\end{array}$ & $\begin{array}{c}\text { Medically } \\
\text { indicated } \\
\text { preterm } \\
\text { delivery }\end{array}$ & $\begin{array}{c}\text { Preterm } \\
\text { labour }\end{array}$ & $\begin{array}{c}\text { Total preterm } \\
\text { births }\end{array}$ \\
\hline $20-33$ & $n$ & 42 & 20 & 55 & \\
& eRR $\neq$ & 2.7 & 2.1 & 2.4 & 130 \\
$34-35$ & $\mathrm{CI} \neq$ & $1.2-6.4$ & $0.7-6.4$ & $1.2-5.1$ & $1.8-4.7$ \\
& $n$ & 31 & 16 & 62 & 126 \\
& $\mathrm{eRR}$ & 2.4 & 1.2 & 1.4 & 1.8 \\
36 & $\mathrm{CI}$ & $1.0-5.7$ & $0.4-4.2$ & $0.7-2.6$ & $1.1-2.7$ \\
& $n$ & 38 & 19 & 63 & 132 \\
& $\mathrm{eRR}$ & 1.1 & 3.4 & 1.3 & 1.6 \\
& $\mathrm{CI}$ & $0.5-2.5$ & $1.1-10.2$ & $0.7-2.6$ & $1.0-2.5$ \\
\hline
\end{tabular}

* Includes 42 preterm births with undetermined aetiology.

+ Adjusted for age, education, gravity, marital status, and county of residence.

$\ddagger \mathrm{eRR}$ estimated relative risk; $\mathrm{CI}=95 \%$ confidence interval.

the same five demographic variables were included in the model, black women were at the highest risk of having a preterm birth before 34 weeks of gestation $(R R=$ $2.9 ; 95 \% \mathrm{CI} 1.8,4.7)$, and this trend was consistent for each aetiologic pathway except for medically indicated preterm delivery. The risk of medically indicated preterm delivery at 36 weeks was considerably higher for black women than for white women $(\mathrm{RR}=3.4 ; 95 \% \mathrm{CI} 1.1,10.2)$.

\section{Discussion}

To date, epidemiologists have failed to identify the risk factors that account for the increased risk of preterm births among black women. In this study, after adjusting for demographic confounders, we found that black women had twice the risk of delivering before 37 weeks of gestation than white women. This risk increased to 2.9 times for very early preterm births $(<34$ weeks) and decreased to 1.6 times for slightly preterm births ( 36 weeks). Because the increased risk of preterm birth was concentrated in the very high-risk early preterm deliveries, aggregate black/white differences in preterm delivery understate the magnitude of the problem.

Medically indicated preterm delivery was a surprisingly strong contributor to the disproportionately high risk of preterm delivery at 36 weeks among black women compared with white women. Adams $e t$ al., in a study of black and white military women who presumably all had equal access to prenatal health care of similar quality, also found that the increased risk for preterm delivery was entirely attributable to differences in the risk of medical intervention to initiate delivery 
among black women. ${ }^{8}$ In our study, one possible explanation for the increased risk of medically indicated preterm delivery among black women at 36 weeks gestation (Table 5) relates to the increased risk of pregnancy complications among black women. Chronic hypertension during pregnancy is known to be a risk factor for abruptio placentae, superimposed pre-eclampsia, and intrauterine growth retardation (IUGR). ${ }^{16}$ Moreover, the excess risk of hypertension among the black population has been well described, although pregnancy-induced hypertension is not necessarily increased. ${ }^{17-20}$ Black pregnant women with medical complications such as hypertension may have had labour induced at 36 weeks because of their excess risk for abruptio placentae, superimposed pre-eclampsia, and IUGR; these women would have delivered at a time when the health risks for their infants would be minimal.

Our finding that the risk of preterm labour and preterm premature rupture of membranes at the earliest gestational ages is higher among black women than among white women is consistent with the results of several other investigators. ${ }^{8,11}$ Kempe et al. studied black and white infants weighing 500-1499 g (very low birthweight) who were born in Boston, St Louis, and Mississippi. ${ }^{11}$ They reported higher proportions of black infants with very low birthweight related to preterm premature rupture of membranes and idiopathic preterm labour as well as other major complications of pregnancy. Similarly, in the study of women enlisted in the military, Adams et al. reported an increased probability of preterm delivery for black infants at the earliest gestations. ${ }^{8}$

Generally, the proportions of preterm birth that we could attribute to preterm premature rupture of membranes $(29 \%)$ or preterm labour (46\%) fit within the range reported in a review of the literature. ${ }^{9}$ Only the proportion of preterm births that we found to be related to medical indications $(13 \%)$ was less than the proportions reported by several other investigators ( $18.7 \%$ to $35.2 \%$ ), although we excluded multiple gestations whereas some previous studies did not.,921-23

Unfortunately, we were unable to analyse all potential confounders for preterm birth, given inherent limitations in the birth certificate data. Consequently, data on smoking, sexually transmitted diseases, stress and other factors were excluded from this analysis. The lack of data on smoking is of some concern in light of recent reports of the potential effect of smoking on the risk of preterm premature rupture of membranes and its association with overall increased risk of spontaneous preterm birth. ${ }^{24-26}$ Subsequent studies that focus on smoking and other variables may contribute to a broader understanding of the differences in the rates of preterm birth for black and white women.

Of more concern is the potential for misclassification of a pregnancy as preterm or the inadvertent exclusion of a preterm pregnancy if the expected date of delivery was incorrectly calculated. We attempted to minimise this second source of bias by routinely evaluating the gestational age of all births reported in the obstetrical log book as having occurred at exactly 37 weeks gestation to confirm that no 'rounding 
up' of gestational age had resulted. Although we cannot determine with absolute certainty whether any differential misclassification of gestational age occurred in this study, we expected the error in the gestational age estimate to be low because ultrasound was often used to verify and correct the estimate. We believe that the gestational age confirmed by ultrasound was a more reliable and valid measurement. Nevertheless, the absolute accuracy of any method of calculating gestational age has been the subject of much debate. ${ }^{27-34}$ Although errors in measurement of gestational age could have biased the results of this study, no evidence exists to indicate that a systematic error in determining length of gestation occurred. Since the design of the algorithm followed in this study to measure length of gestation was influenced by the prevailing obstetrical practices reported in the epidemiological literature, it is believed that misclassification of gestational age was minimal.

Another potential source of bias which we were not able to avoid were exclusions as a result of home deliveries. These deliveries could have represented precipitous preterm labour. We found that white women were slightly more likely than black women to have delivered at home or in a hospital outside the study area ( $3.9 \%$ vs. $1.8 \%$ respectively). However, because the numbers were relatively small and no overall trend toward exclusion was observed for preterm births $(<37$ completed weeks gestation) compared with term births $(=>37$ completed weeks gestation) as recorded in vital records, we felt it was unlikely for substantial bias to have occurred.

Investigating the risks for each pathway of preterm delivery is an initial step toward elucidating the determinants of the increased risk for preterm delivery among black women. Our findings are consistent with recent evidence that points to diverse aetiological pathways as contributing factors.,11,26,35 These results suggest that future research should focus on identifying risks for different gestational age groups. Prevention techniques, to be most effective, should change during pregnancy to adapt to the predominating risk factors noted at varying gestational ages. Race-specific effects of antepartum maternal medical complications have been reported to contribute differentially to the risk of very low birthweight that virtually always is accompanied by preterm delivery. ${ }^{36}$ Thus, intervention strategies should specifically address underlying health risks that are more common among black women, that may complicate a pregnancy, and that ultimately lead to a medically indicated preterm delivery. A single risk factor such as infection, even combined with economic deprivation, is unlikely to account for all of the excess risk for preterm delivery among black women. The psychosocial, sociocultural and environmental context within which black women live and within which their pregnancies occur also warrant closer evaluation..$^{37-40}$ 


\section{Acknowledgements}

The authors are grateful to the project managers, Kate Brett and Laurie Elam Evans, record abstracters, Angela Burrows, Josephine Evans, Annie Hodges, Suzanne Jackson, Catherine Mohin, and Cheryl Watkins, and computer programmers, Kim Allee, Missy Jamison and Nancy Dole Runkle. This study was supported by a grant from the National Institutes of Health, USA and the March of Dimes Birth Defects Foundation, USA. An earlier version of this paper was presented at the 25th annual meeting of the Society for Epidemiologic Research, held in Minneapolis, Minnesota, USA, June 9-12, 1992.

\section{References}

1 Centers for Disease Control. Infant mortality - United States, 1990. Morbidity and Mortality Weekly Report 1993; 42:161-45.

2 National Center for Health Statistics. Advance report of final natality statistics, 1990. Monthly Vital Statistics Report 1993; 41(suppl):1-52.

3 Behrman RE. Premature births among Black women (Editorial). New England Journal of Medicine 1987; 317:763-765.

4 Hogue CJR, Yip R. Preterm delivery: can we lower the Black infant's first hurdle? Journal of the American Medical Association 1989; 262:548-550.

5 Lieberman E. Ryan KJ, Monson RR, Schoenbaum SC. Risk factors accounting for racial differences in the rate of premature birth. New England Journal of Medicine 1987; 317:743-748.

6 Shiono PH, Klebanoff MA. Ethnic differences in preterm and very preterm delivery. American Journal of Public Health 1986; 76:1317-1321.

7 McGrady GA, Sung JFC, Rowley DL, Hogue CJR. Preterm delivery and low birth weight among first-born infants of Black and White college graduates. American Journal of Epidemiology 1992; 136:266-276.

8 Adams MM, Read JA, Rawlings JS, Harlass FB, Sarno AP, Rhodes PH. Preterm delivery among Black and White enlisted women in the United States Army. Obstetrics and Gynecology 1993; 81:65-71.

9 Savitz DA, Blackmore CA, Thorp JM. Epidemiology of preterm delivery: etiologic heterogeneity. American Journal of Obstetrics and Gynecology 1991; 164:467-471.

10 Tucker JM, Goldenberg RL, Davis RO, Copper RL, Winkler CL, Hauth JC. Etiologies of preterm birth in an indigent population: is prevention a logical expectation? Obstetrics and Gynecology 1991; 77:343-347.

11 Kempe A, Wise PH, Barkan SE, Sappenfield WM, Sachs B, Gortmaker SL, et al. Clinical determinants of the racial disparity in very low birth weight. New England Journal of Medicine 1992; 327:969-973.

12 Herron MA, Katz M, Creasy RK. Evaluation of a preterm birth prevention program: preliminary report. Obstetrics and Gynecology 1981; 59:452-456.

13 Main DM, Gabbe SG, Richardson D, Strong S. Can preterm deliveries be prevented? American Journal of Obstetrics and Gynecology 1985; 151:892-898.

14 Gonik B, Creasy RK. Preterm labor: its diagnosis and management. American Journal of Obstetrics and Gynecology 1986; 154:3-8.

15 Kleinbaum DG, Kupper LL, Morgenstern H. Epidemiologic Research Principles and Quantitative Methods. Belmont, CA: Lifetime Learning Publications, 1982.

16 Roberts JM, Pregnancy-related hypertension. In: Maternal-fetal Medicine: Principles and 
Practice. Editors: Creasy RK, Resnik R. Philadelphia: W.B. Saunders Company, 1989; pp. 777-813.

17 Hypertension Detection and Follow-up Program Cooperative Group. Race, education, and prevalence of hypertension. American Joumal of Epidemiology 1977; 106:351-361.

18 James SA, Strogatz DS, Wing SB, Ramsey DL. Socioeconomic status. John Henryism, and hypertension in Blacks and Whites. American Journal of Epidemiology 1987; 126:664-673. 19 James SA, Keenan NL, Strogatz DS, Browning SR, Garrett JM. Socioeconomic status, John Henryism, and blood pressure in Black adults. American Journal of Epidemiology 1992; 135:59-67.

20 Stamler J, Stamler R, Riedlinger WF, Algera G, Roberts RH. Hypertension screening of 1 million Americans: Community Hypertension Evaluation Clinic (CHEC) Program, 1973 through 1975. Journal of the American Medical Association 1976; 235:2299-2306.

21 Meis PJ, Ernest JM, Moore ML. Causes of low birth weight births in public and private patients. American Journal of Obstetrics and Gynecology 1987; 156:1165-1168.

22 Arias F, Tomich P. Etiology and outcome of low birth weight and preterm infants. Obstetrics and Gynecology 1982; 60:277-281.

23 Piekkala P, Kero P, Erkkola R, Sillanpää M. Perinatal events and neonatal morbidity: an analysis of 5380 cases. Early Human Development 1986; 13:249-268.

24 Harger JH, Hsing AW, Tuomala RE, Gibbs RS, Mead PB, Eschenbach DA, et al. Risk factors for preterm premature rupture of fetal membranes: a multicenter case-control study. American Journal of Obstetrics and Gynecology 1990; 163:130-137.

25 Williams MA, Mittendorf R, Stubblefield PG, Lieberman E, Schoenbaum SC, Monson RR. Cigarettes, coffee, and preterm premature rupture of the membranes. American Journal of Epidemiology 1992; 135:895-903.

26 Kramer MS, McLean FH, Eason EL, Usher RH. Maternal nutrition and spontaneous preterm birth. American Journal of Epidemiology 1992; 136:574-583.

27 Ballard JL, Kasmaier K, Driver M. A simplified assessment of gestational age (Abstract). Pediatric Research 1977; 11:374.

28 Ballard JL, Novak KK, Driver M. A simplified score for assessment of fetal maturation in newly born infants. Journal of Pediatrics 1979; 95:769-774.

29 Berkowitz GS. An epidemiologic study of preterm delivery. American Journal of Epidemiology 1981; 113:81-92.

30 Berkowitz GS. Clinical and obstetric risk factors for preterm delivery. Mount Sinai Journal of Medicine 1985; 52:239-247.

31 Dubowitz L, Dubowitz V, Goldberg C. Clinical assessment of gestational age in the newborn infant. Journal of Pediatrics 1970; 77:1-10.

32 Goldenberg RL, Davis RO, Cutter GR, Hoffman HJ, Brumfield CG, Foster JM. Prematurity, postdates, and growth retardation: the influence of use of ultrasonography on reported gestational age. American Journal of Obstetrics and Gynecology 1989; 160:462-470.

33 Jimenez JM, Tyson JE, Reisch JS. Clinical measures of gestational age in normal pregnancies. Obstetrics and Gynecology 1983; 61:438-443.

34 Kramer MS, McLean FH, Boyd ME, Usher RH. The validity of gestational age estimation by menstrual dating in term, preterm, and postterm gestations. Journal of the American Medical Association 1988; 260:3306-3308.

35 Berkowitz GS, Papiernik E. Epidemiology of preterm birth. Epidemiologic Reviews 1993; 15:414-443.

36 DeBaun MR, Rowley D, Province M, Stockbauer JW, Cole FC. The race-specific effects of antepartum maternal medical complication on the incidence of very low birthweight (VLBW) infants [Abstract]. Paediatric and Perinatal Epidemiology 1993; 7:A23. 
37 David RJ, Collins JW. Bad outcomes in Black babies: race or racism. Ethnicity and Disease 1991; 1:236-244.

38 Davidson EC, Fukushima T. The racial disparity in infant mortality (Editorial). New England Journal of Medicine 1992; 327:1022-1024.

39 Rowley DL, Hogue CJR, Blackmore CA, Ferré CD, Hatfield-Timajchy K, Branch P, et al. Preterm delivery among African-American women: a research strategy. American Journal of Preventive Medicine 1993; 9(supplement 2):1-7.

40 Blackmore CA, Ferré CD, Rowley DL, Hogue CJR, Gaiter J, Atrash H. Is race a risk factor or a risk marker for preterm delivery? Ethnicity \& Disease 1993; 3:94-109.

\section{Book review}

Handbook of Neuroepidemiology. Editors: P. B. Gorelick $\mathcal{E}$ M. Alter. New York: Marcel Dekker, 1994, pp. 623, US\$ 185.

This expensive (\$185/£116) multi-author book is a good source of information about neuroepidemiology. Unfortunately, relatively little of this book will be attractive to those who study the epidemiology of perinatal and pediatric disorders. To a large extent this reflects the emphasis on neurological disorders that tend to occur in adults, including ischaemic stroke, Alzheimer's disease, vascular dementia, Parkinson's disease, peripheral neuropathy, motor neurone disease, multiple sclerosis, and brain injury in boxing. The existence of children is acknowledged in some tables showing age-specific incidence and prevalence. On the other hand a number of chapters deal with topics devoted mainly to adults but with opportunities to discuss the occurrence of the disorder in children. For example, the approximately 30 pages of text in the chapter on epilepsy have paragraphs dealing with West syndrome, Lennox-Gastaut syndrome, febrile seizures, the association of epilepsy with motor and cognitive disorders, but do not have anything on neonatal seizures. The chapters on intracranial neoplasia and headache address little attention to childhood expressions of these disorders.

What I found particularly attractive about this book is the commentary that accompanies every chapter. These are provided not by the editors, but rather by a person highly knowledgeable about each of the fields.

The chapters on encephalitis and bacterial meningitis do have components that are likely to be of interest to some readers of Paediatric and Perinatal Epidemiology. For those who are looking for information about the epidemiology of brain and spinal cord malformations, neonatal hydrocephalus, neonatal intracranial haemorrhage, neonatal white matter damage, neonatal seizures, developmental delay, cerebral palsy, learning disabilities, etc., will need to seek guidance elsewhere. 